\title{
Analysing high technology adoption and impact within public supported high tech programs: An empirical case
}

\author{
José Albors-Garrigos , José Luis Hervas-Oliver , Antonio Hidalgo \\ Univ. Pol. Valencia, Dept. Org. Empresas, Spain \\ Univ. Pol. Madrid, Dept. Ing. Organización, Spain
}

\section{A R T I C L E I N F O}

Keywords:

High tech

Public innovation policies

\begin{abstract}
A B S T R A C T
The aim of this paper is to contribute to the body of knowledge in relation to the diffusion and adoption process of high technology. It intends to analyse those mechanisms that influence advanced technology transference and marketing, and those features that improve the impact of public programs supporting the adoption of high technology. The paper proposes a contingent construct that explains how advanced technology is transferred, diffused and adopted by users in a firm. In relation to the impact of technology transference this paper follows a novel approach: value mapping methodology adapted to the case of advanced technology. The article provides empirical evidence on the variables which contribute to the technology transference and commercialization process, and especially in the case of SMES. Key variables such as technology complexity, relationships between researchers, developers and final users, as well as market barriers appear to be critical for the transference process. Moreover, technology absorption by incumbent firms becomes a necessary requirement for its subsequent transfer.

The paper has utilised the available experience from the GAME initiative, part of the European Commission IV Research Framework Programme, related to the promotion of microelectronics among Spanish firms. Using a representative sample and employing multivariable analysis methods, a model was developed in order to understand technology diffusion, absorption and transference knowledge flows. In addition, the model is useful for evaluating technology dissemination using the diffusion model to measure its social impact. The paper found that social impact can be explained by the creation of employment.
\end{abstract}

\section{Introduction. State of the Art in Advanced Technology Diffusion}

\subsection{Objectives of the study}

The objectives of this paper are to contribute to the analysis of the adoption process and social efficiency of high technology diffusion public programs and policies as well as to the understanding of the mechanisms that influence the process of high technology transference. To achieve this we have drawn on the theory of innovation and technology development in order to understand the context of high technology diffusion and its variables which influence the process. In order to evaluate the effectiveness of the diffusion we have followed the contingent model proposed by Bozeman (2000) and the methodology of value mapping as a means of measuring the program impact, i.e., how high tech products are developed and the process of technology adoption. 
The specific objective of the paper is to develop a construct that facilitates the analysis of the diffusion of advanced technology programs and to identify those variables that have a significant impact in the process. There are a number of research questions to be answered: Is high tech product development different from conventional new product development? Which elements in the development and adoption processes are relevant? How can we measure the impact of public supported programs for the diffusion of advanced technology? Is this impact dependent on the development process?

In this case, advanced technology diffusion has to deal with three basic difficulties (Tatikonda \& Rosenthal, 2000a,b). First its complexity makes it very difficult to communicate and transfer. Secondly, it is subject to drastic and frequent changes due to technology disruption and economic conditions. Finally, project development becomes complex due to task uncertainty.

In order to achieve the proposed objective the paper is organized as follows: following the introduction we review specific literature and the hypotheses are stated according to the theoretical framework. Then, we describe the field case (GAME program) and present the methodology and empirical design, with the model and variables used as well as the characteristics of the sample. Finally, the results of the empirical evidence are given. Conclusions and a discussion are provided in the last part of the article.

\subsection{Conceptual approach. Technology diffusion theories and policies}

\subsubsection{Technology diffusion and adoption. Context and market conditions}

The classical theory of innovation diffusion was based on sociology and was designed by Rogers in a seminal publication (Rogers, 1995). He proposed and confirmed the well-known S-shaped diffusion curves as well as the bell curve classifying the adopter's profiles. Since then adoption has been considered as part of the diffusion process and also a measure of its success. Other authors have studied the phenomena, applying the theory to technology diffusion. Bass (1969) provided a classical model which has received widespread attention. Roberts and Lattin (2000), Mahajan, Muller and Bass (1991) have studied and surveyed the technology literature which is mainly based on market data.

The sociological school explains diffusion as an epidemic model of learning by consumers. Some authors still support these effects in technology adoption models (Gourlay \& Pentecost, 2002). Other alternative models consider consumer heterogeneity as the driving force which influences the diffusion process (Davies, 1979). The S-adoption curve was shaped by the values placed on the new product by potential adopters. More recently, the prevailing school of thought has supported probit models where the differences in adoption reflect the differences in the goals, needs and abilities of firms and final users (Geroski, 2000).

In the case of high or advanced technology, and in relation to the adoption process, some authors have pointed out the relevance of technology in the early diffusion stages versus the relevance of solutions and convergence in the later mature stages (Norman, 1998). However, some authors have pointed out the irrelevance of a competitive environment and technology versus the innovative drive of the firm (Yang \& Liu, 2006). Others have highlighted the perception of active high tech users (Green, Collins, \& Hevner, 2004). However, in relation to project development as far as high tech product development is concerned, the majority of authors take into account the relevance of technology complexity and uncertainty (Tatikonda \& Rosenthal, 2000a,b). Here, since we are considering microelectronics, the technology complexity is associated with the service innovative capability provided, whether it means a radical innovation or a rather incremental innovation (Subramanian \& Youndt, 2005; Chandy \& Tellis, 2000).

From the point of view of technology adoption, Hall and Khan (2003) indicate how it is influenced by demand behaviour, network effects, supply behaviour, environmental factors as well as by government and regulations. Sirgy and Su (2000) have analysed how high tech contexts are increasingly responsible for changes in the opportunity, ability, and motivation of consumers to adopt innovations. Christensen (1997) has studied resistance by firms to adopt disruptive technologies because they are not well suited to their current customer's present needs. Decter, Bennett and Leseure (2007) have studied the perceived barriers of university research centres to business technology transfer and offered suggestions for possible improvements in the process. Greiner and Franza (2003) have considered key barriers and bridges in the case of the transfer of environmental technologies, including regulations, difficulty in clearly defining the end-user needs, and the need to demonstrate technologies to potential endusers. These authors provide recommendations for improving the technology transfer process.

The changes in a customer's drive in the technology diffusion process have been described by Moore (1991) from a marketing point of view, departing from the Rogers bell curves. This contribution relies on a detailed description of the final user's needs and profiles. A more integrative approach has been suggested by Malhotra (1999) considering the whole of the adoption processes in the case of IT adoption. Cooper and Bruno have analysed how high tech SMESs cope with technology diffusion in their markets, and Crick and Jones (2000) on their approach to international markets. Im and Workman (2004) have analysed how market orientation, creativity, and new product performance in high technology firms are key to the success of a firm when there is a necessity to respond to changing market needs.

Some authors (Venkatesh \& Davis, 2000) have developed a technology acceptance model (TAM) where job relevance, output quality, result demonstrability, and perceived ease of use significantly influenced user acceptance.

In relation to the actors - research centres and firms - concerned in the process of technology and knowledge transfer, Sung and Gibson (2005) have outlined four key factors to accelerating knowledge and technology transfer: Communication, Distance, Equivocality, and Motivation. Arvanitis, Kubli and Worter (2005) explored the factors determining the propensity of Swiss firms to interact with public science institutions in Switzerland in the transfer of knowledge and technology through training, recruitment of R\&D personnel, research, consulting, etc. The study outlined the transfer of "tacit" knowledge as well the relevant motivation of firms and research centres. Santoro and Gopalakrishnan (2001) have analysed relationship-oriented factors such as trust, geographic proximity, communication, and research centre policies and how these factors influence the technology transfer 
process between research centres and their industrial partners. Also, in relation to the influence of research centres, according to Link and Scott (2003) there is a direct relationship between the proximity of the firms to the research centres and the probability that the latter will shift their focus from basic to applied research.

\subsubsection{Technology transfer versus technology absorption}

We have adopted the definition of technology transfer as an "intentional, goal-oriented interaction between two or more social entities, during which the pool of technological knowledge remains stable or increases through the transfer of one or more components of technology." (Autio \& Laananen, 1995). Technology transfer is therefore considered to be an active process, during which technology traverses the borders between two entities. These entities can be countries, companies, or even individuals. Thus, technology transfer involves not only the explaining of the knowledge associated with the technology but also a feedback process between the parties (Kremic, 2003).

In relation to technology transfer, Stock and Tatikonda $(2004,2008)$ have proposed a contingent model of the technology transfer process based on technology management literature. According to these authors, technology integration will be most successful when the level of interaction between the source of the technology and the recipient of the technology is appropriately matched to, or fit, the characteristics of the technology to be integrated. Moreover, the organizational structure of the recipient will have to match both technology and recipient.

The concept of technology absorption has been defined by Kingsley and Farmer (1997) as the internal use of a technology or knowledge developed in a R\&D project by a participant, subcontractor or sponsor. It may be considered a feedback of the process opposite to the technology transfer, an output of the whole technology diffusion process (Kremic, 2003).

\subsubsection{Technology policies}

Technology policy has been defined (Mowery, 1995), as "policies that are intended to influence the decisions of firms to develop, commercialise or adopt new technologies". It should be pointed out that the design and evaluation of technology policies is a complex process for various reasons, such as for example, the characteristic and tacit dimension of communicating technological knowledge (which some authors refer to as software aspects), the aspects related to the appropriateness of the returns, the frequent inconsistency of the policy goals which call for compromise among conflicting objectives and the difficulty of measuring the results and hence their efficiency (Teece, 1981; Stoneman \& Vickers, 1988).

Technology policies could be classified either as "supply policies" which tend to support the creation phases of the technology development process and "adoption policies" which concentrate on the support of the diffusion and application of new technologies. Some authors (Ergas, 1987) have strongly supported the benefits of the latter and others (David, 1986) have pointed out the conflict between both policies.

Bozeman (2000) has analysed the role of public policies in technology adoption as correctors of market unbalances. Kerr and Newell (2003) have analysed the impact of regulations and tax incentives in technology adoption. Regarding SME-focalised supporting programs centred on overcoming technology adoption, Estrin and Foreman (2003) have analysed sectoral technology adoption public policies in the USA and how they can improve adoption efficiency. Hahn and Yu (1999) have proposed a technology policy aimed both at generation and diffusion of advanced technologies.

Audretsch, Link and Scott (2002) analyse how public programs (in the case of the Department of Defense's Small Business Innovation Research Program) can catalyse technology adoption and diffusion and coordinate synergies of the R\&D centres and firms towards common objectives. These authors also conclude in a positive social impact outcome of technology transfer and commercialization in the programs with a clear R\&D stimulation as well.

\subsection{Advanced technology impact analysis. Value mapping methodology}

In relation to the evaluation of public programs supporting advanced technology, Georghiou and Roessner (2000) have carried out a comprehensive review of the analytical tools and methods for the evaluation of public programs intended to stimulate advanced technology. Both authors conclude that the program's impact evaluation has had a lower coverage by academic literature than it should, mainly due to its practical nature and the scarcity of information on valuable work and methods. Moreover, program evaluation and performance reviews, in spite of their distinctive objectives, measures, and tools, have been analysed together and the boundaries between both have become unclear. Additionally, there are new research lines which seem promising for evaluating a program's impact based on linkages between knowledge generators and users, as well as that of the program networks.

Various authors (i.e. Campbell, Shipp, Mulcahy, \& Allen, 2009; Feldman \& Kelley, 2003; Link, 1993) have made a broad analysis of the impact of the Advanced Technology Program in the USA. This is a well-known program ${ }^{1}$, a high impact program with a robust influence in the US economy. The mentioned authors classify its impact according to the time horizon as follows:

(a) Short term: partnerships and knowledge sharing; increased and acceleration of R\&D spending; and technical accomplishment (milestones, papers, patents).

(b) Medium term: commercialization alliances; attraction of capital; new products and processes; and employment growth.

(c) Long term: changing core competencies; inter- and intra-industry diffusion; societal impacts - health, security, competitiveness; increased national output; and positive public ROI. 
The contribution of advanced technology programs to a firm's competitiveness and new working procedures has been pointed out by Ghani, Jayabalan and Sugumar (2002). Some authors such as Cooke, Davies and Wilson (2002), Dohse (2000) and Eickelpasch and Fritsch (2005) have considered the impact of advanced technology on regional development, and Pavelin and Porter (2008) studied the social impact of innovation on firms while Quetglás and Grau (2002) or Rogers (2004) studied the impact of university research on high tech firms based on advanced technology in new employment creation.

In this case, and as a model for impact analysis, we have selected Research Value Mapping (Bozeman and Kingsley, 1997; Kingsley et al., 1996; Kingsley and Farmer, 1997; Kingsley and Melkers, 1999) as a conceptual approach, quite useful for judging the global impact of technology research.

This method (henceforth referred to as RVM) goes beyond the classical research evaluation that focuses only on the outputs of research by also focusing on the impacts of these outputs. Moreover, in considering the impacts of publicly supported research, a relevant driving motivation is an understanding of social impacts and outcomes, in addition to the more studied scientific or economic impacts of publicly supported research.

\section{Development of hypotheses}

When considering technology diffusion, there are two schools of thought in the theoretical discussion. One follows an epidemic model where there is a high degree of homogeneity among firms or consumers in the adoption of a technology (Rogers, 1995; Geroski, 2000, etc.). The alternative suggests a probit model where a certain heterogeneity among firms exists in relation to technology adoption according to social structures, information transmission, size of the firm, suppliers, learning costs, skills, relationships, etc. proposing various contingent models (Gatignon \& Robertson, 1989; Geroski, 2000; Hall and Khan, 2003, etc.). This leads to

Hypothesis 1. The process of advanced technology diffusion follows a heterogeneous path among the firms where various factors influence the diffusion process.

As has been mentioned previously, final adoption and transfer of technology can be contingent with various factors of the firm such as organization technology and complexity, project organization (Stock \& Tatikonda, 2004, 2008), size, markets, industry complexity, and learning costs, (Gatignon and Robertson, 1989; Geroski, 2000; Hall and Khan, 2003; etc). From here the second proposition can be drawn:

Hypothesis 2. The advanced technology adoption and transfer process will follow a contingent model dependent on various factors of the firm such as size, markets, industry complexity, organization, technology and complexity, project organization, etc.

The literature points out that the efficiency of the advanced technology transference programs can be measured by their social impact and by the degree to which the technology is absorbed by incumbent firms and transferred to third parties by the recipient firms (Bozeman and Kingsley 1997; Kingsley et al., 1996; Kingsley and Farmer, 1997; Kingsley and Melkers, 1999). Consequently,

Hypothesis 3. The efficiency of technology adoption process can be measured by the degree to which it has been absorbed and/or transferred by the firm.

Finally, and following Campbell et al. (2009), Link (1993), Feldman and Kelley (2003), Pavelin and Porter (2008), Rogers (2004) and Quetglás and Grau (2002), we can draw the fourth hypothesis:

Hypothesis 4. The social impact measured in employment creation will be correlated with the efficiency of technology adoption.

\section{The GAME program}

\subsection{Background}

GAME is the acronym for Grupo Activador de la Microelectronica en España (Activating group for Spanish microelectronics). At the end of 1989 the Spanish central government and regional officers in charge of technology programs initiated a series of meetings in order to correct the low level of participation in the utilisation of microelectronics in the Spanish industry, especially in SMEs. A new program, supported partially by European Commission, was set up in order to correct the situation. The goals of the program were rather modest - they sought a steady improvement of the state of the industry rather than dramatic accomplishments. The emphasis on internationalisation and its European projection, through collaboration with European industry and research centres, as well as the fact that the European Commission provided 50\% of the funds, complicated somewhat the development of the program.

It must be said that microelectronics technology was subject to relevant disruptions in the 1990s and that recent technology developments have changed its technological environment.

As an example of the awareness in this area of Spanish firms, only $10 \%$ of the firms surveyed in the field study had had contact with the supported technology or had actually used it. The rest were either unaware or had very limited experience with it (Fundación Cotec, 1997). The regional distribution showed that most of the firms aware of this technology were concentrated in large cities. 
The main participants involved in the action were the following:

- The firms, as the final objective of the action;

- Support (research) centres, which had the role of diffusing the technology, identifying potential customers (firms), offering technical advice on the feasibility of certain applications, and organizing demonstration workshops. Some of them were also design centres, responsible for the design of the circuits;

- The Companies which manufactured the integrated circuits; and

- The Co-ordinating Agent, who managed the project.

As we will discuss later, 120 firms and 26 supporting research centres participated in the action, 50\% of which were able to successfully conclude the entire development process, although the degree of participation varied considerably. Finally, 10 European companies participated in the program, also to varying degrees.

\subsection{Development of the program}

Fig. 1 below summarises the phases of a typical project. Since the circuit design and production phases may be quite costly, a feasibility study had to be carried out which involved the use of complex design and simulation software programs. Also, in order to test the circuit it was sometimes necessary to build short series before making a final decision. Not all the support centres (research centres and university groups) had the skills, training, infrastructure or qualifications to carry out all these phases, although some were able to create them during the project, as will be seen later.

The program spanned a period of six years, from 1990 to 1996. Fig. 2 shows the basic milestones of the program, which ran in two phases. The first, which lasted three and a half years, was managed by the AENTEC agency, contracted by the Spanish Ministry of Industry. The second was managed by a non-profit organisation - The Cotec Foundation - which focuses on the promotion of technology innovation. The second phase, which had not been envisaged previously, benefited from the experience obtained in the first.

The second phase was characterised by the program's internationalisation efforts since the supporting groups participated in European projects (ESPRIT) as well as in exchange programs with other European research groups. The budget for the first phase was $€ 8750$ million and $€ 10,030$ million for the second. The second phase was more efficient since during the first phase only 51 projects out of 68 proposals were approved while during the second, 104 proposals were submitted of which 75 were approved.

The main actions related to the program were as follows:

Promotion. The support organization, composed of support centres and in some cases consultants, carried out a number of seminars, workshops, visits to potential users in order to diffuse, inform, diagnose potential applications of microelectronics technology, etc. Other centres prepared material, specifications, manuals describing the advantages of the technologies as well as success stories of the developed projects, etc. Special efforts were required in order to decentralize the initiative. Firms from only five Spanish regions participated in the first phase, while in the second phase it was extended to eleven regions.

Taking into account all the workshops carried out in this phase, the number of firms that attended these meetings, or were visited, is estimated to be over 1200 .

Project Management. A technical committee was in charge of analysing the project proposals submitted by firms and support centres. Economical feasibility and technical soundness were the selecting factors. Of the 172 projects proposed, 126 were approved for funding and 100 were completed.

The support centres took care of guiding the project through all the phases shown in Fig. 1. As has already been pointed out, not all the centres were able to carry out all the phases required to complete the project. Some large firms developed their own projects, having the skills and tools to do so.

\subsection{The program outcome}

The efficiency of the program, measured by the unit cost of the finished projects, improved from 213,414 Euros in the first phase to 170,000 Euros in the second, in spite of its higher complexity. As can be observed in Fig. 2, the line which reflects the accumulated number of approved projects suggests an epidemic diffusion curve reflecting the adoption level by the users of the technology.

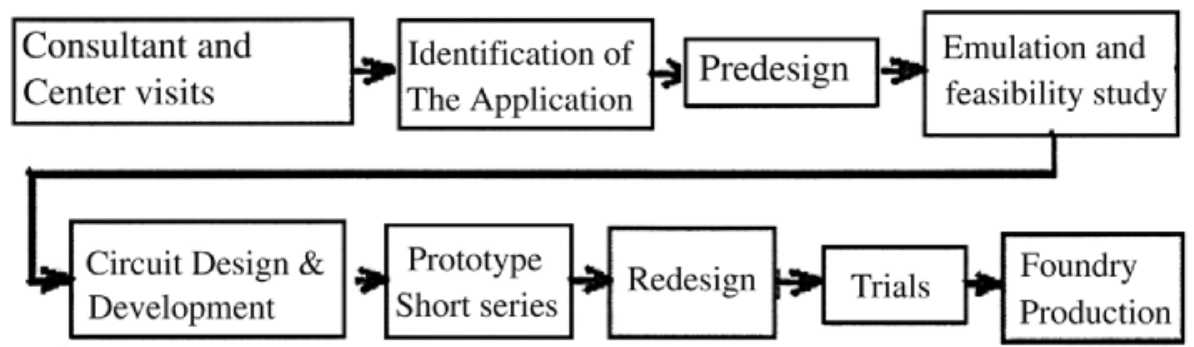

Fig. 1. Typical project phases. 


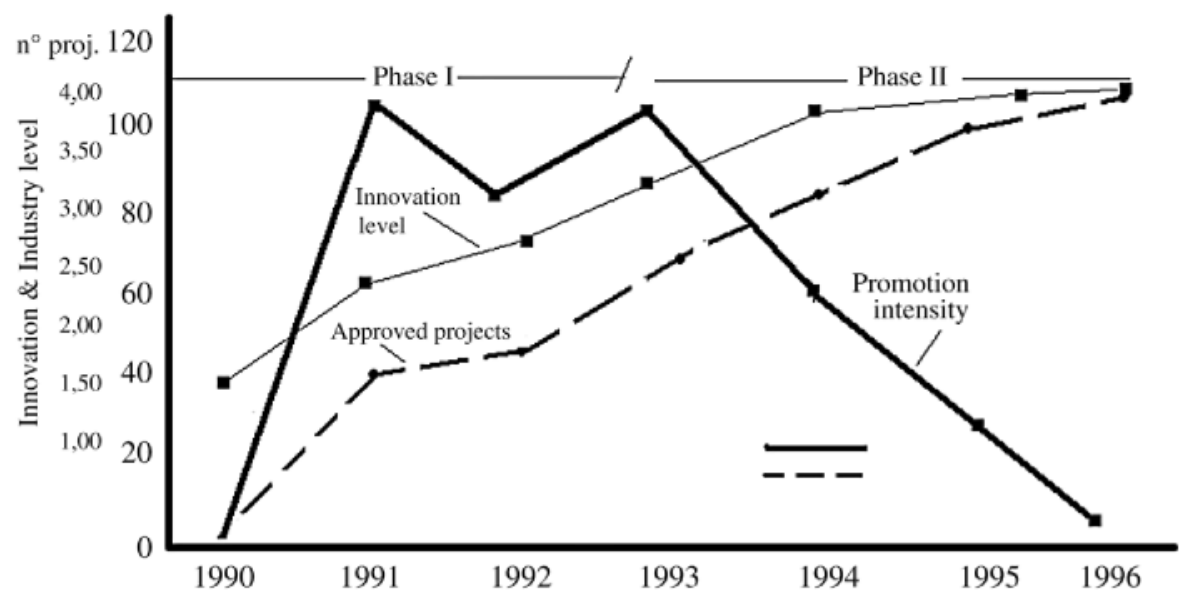

Fig. 2. Evolution of the program.

The projects could be classified in four innovative levels, taking into account the sector of the applicant firm, its innovative approach, the performance of the integrated circuit and its complexity. They were also classified according to their industry production volume (number of final integrated circuits produced). Fig. 2 shows as well the evolution of the technology complexity level throughout the program development, taking into account the percentage of both characteristics in the approved accumulated projects during the course of the programme. The resulting curve is also S-shaped.

These results show that, besides the adoption of the technology by the firms, the adopters follow an adoption curve and are prepared to not only accept the technology performance but also to utilise it for more user-extensive applications.

\subsection{The Program evaluation}

Under the auspices of the Fundación Cotec the authors carried out an evaluation of the program during 2003. In OctoberNovember 2003, interviews were carried out with all the program participants. Interviews were also held with program managers and coordinators as well as with the project managers at the support research centres.

The interviews followed a pattern of detailed questions, which will be discussed below. The questions were related to the project itself, the firm, the relationship with the research centre, and the industry sector on which the project was focused. These questions were related to the context of the project, the output of the project and its consequences.

\section{Empirical design: sample, model and variables}

The methodology is based on the analysis of the empirical information of the GAME program, taken from a set of one hundred cases, collected through personal interviews with the main participants (managers of the program, project managers of the participating firms, research scientists, etc.), as well as with officers of the industry association and from background information. Multivariable analysis was used in order to analyse the data obtained from the survey.

\subsection{The sample}

Out of 172 initial project proposals, 120 projects were selected to participate in the program. Of these, 100 project representatives filled out the questionnaire and participated in the survey with an $83.33 \%$ response rate. All the project managers were contacted, except in $5 \%$ of the cases where other participants served as project managers. In some cases the firm had disappeared and the former project manager was traced and interviewed at his/her new job.

Fig. 3 shows the percentage of firms in the sample according to their size. The program was relatively successful judging by the adoption of the technology by small and medium firms. These firms, in spite of a reluctant attitude towards technology, were capable of adopting sophisticated and complex technology where the "software" elements involved a number of specialists. The participation of firms in the program expanded from $80 \%$ to $86 \%$ from phase I to phase II, and, as the figure shows, this was more evident in the case of medium-size firms (51-250 employees). This fact is important if we consider that the adopted technology evolved towards a higher complexity from one phase to the next and therefore the difficulties involved in the adoption were higher.

The report on the program published by the last program coordinating organization has been utilised (Fundación Cotec, 1997) as a source of detailed technical data for our analysis.

The GAME process is depicted in Fig. 4. The two potential outcomes of the program projects have been differentiated according to the two paths projects can follow: absorption and/or technology transfer. When the developed technology was utilised by third parties, it was thus marketed and went beyond the prototype phase by achieving marketing. The level of transfer was indicated by the production level reached, as well as by the fact that the technology was sold to others. If the technology was not marketed and 


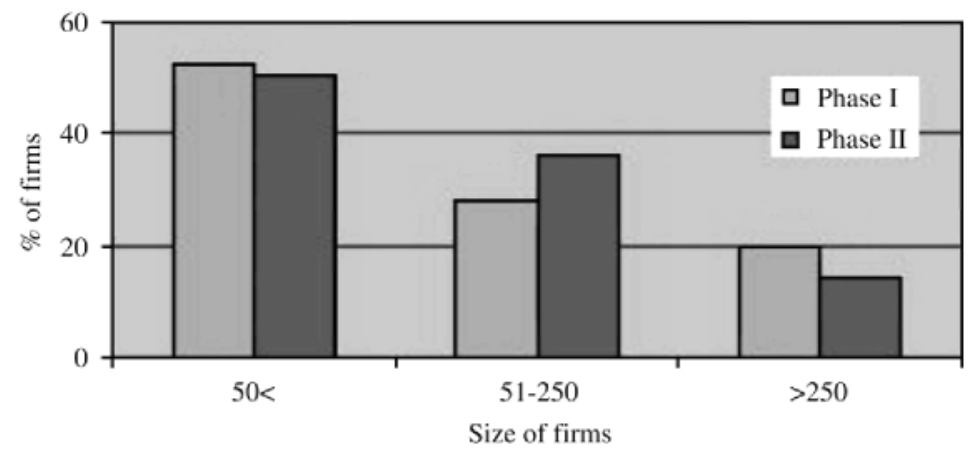

Fig. 3. Size of participant firms.

its utilisation was limited to the research centre and the environment of the firm, we were faced with an absorption case (Kingsley, 1993; Kingsley et al., 1996). The level of absorption could be estimated by the volume of the prototype trials as well as by the relationships with the research centre and the firm's reported project contribution. The third dimension to be considered, the social impact of the project (Kingsley and Melkers, 1999) could be measured by the reported industry impact on the firm's environment as well as by growth of the firm and the employment created.

Hypothesis 3 to be tested implies that, following the RVM model, these high tech projects should be classified in accordance with their technology transfer and technology absorption levels, into four clusters: high technology transfer/high technology absorption, high technology transfer/low technology absorption, low technology absorption and transfer. Thus a matrix should be formed containing the four project groups. Furthermore, we must assess whether this classification is related to their social impact and whether the complex technology characteristics can alter the efficiency of this methodology approach.

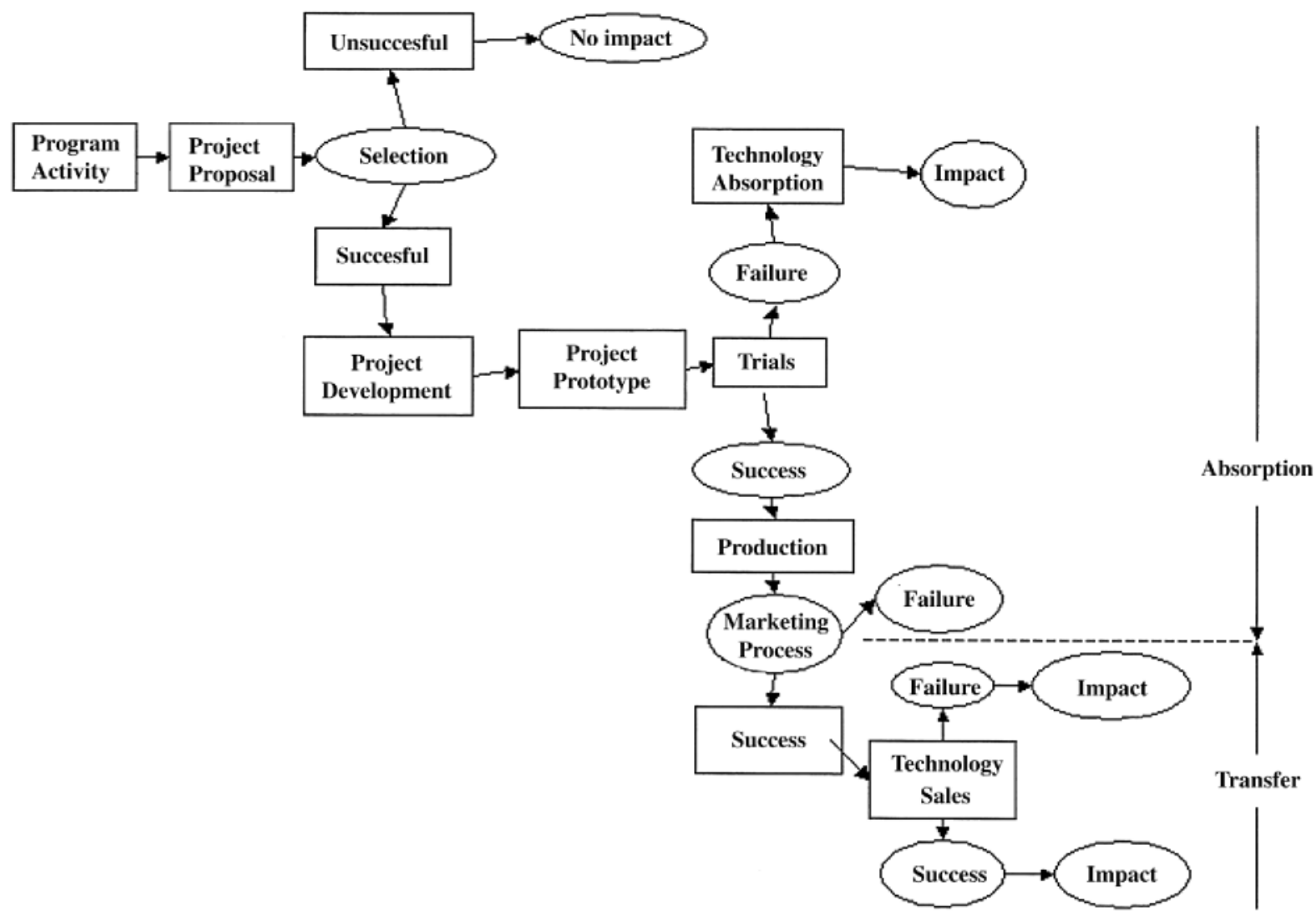

Fig. 4. Technology absorption and transfer processes (adapted from Kingsley et al., 1996). 
Table 1

Survey questionnaire. Variables.

\begin{tabular}{|c|c|c|c|c|}
\hline & Question & Variable & Value scale & References \\
\hline \multirow[t]{6}{*}{ The Project } & Technology complexity & TECHCOMPL V1 & $\begin{array}{l}1 \text { (incremental innovative capability); } \\
\text { to }-4 \text { (radical innovative capability) }\end{array}$ & $\begin{array}{l}\text { Subramanian and Youndt (2005), Chandy and Tellis (2000), } \\
\text { Tatikonda and Rosenthal (2000a,b), Stock and Tatikonda (2004); } \\
\text { Tatikonda and Montoya-Weiss (2001), Stock and Tatikonda (2008), } \\
\text { Tatikonda (1999) }\end{array}$ \\
\hline & Who defined the proposal? & PROPOSER V2 & $\begin{array}{l}\text { 1. Research centre, } 2 \text {. The firm, } \\
\text { 3. Program manager, and } 4 \text {. Final client }\end{array}$ & Reid and de Brentani (2004) \\
\hline & $\begin{array}{l}\text { Where the results marketed } \\
\text { publicly? }\end{array}$ & MARKETED V3 & $1-0$ & $\begin{array}{l}\text { Stock and Tatikonda (2004), Cooper and Bruno (2000), } \\
\text { Kingsley et al. (1996), Kingsley and Farmer (1997), }\end{array}$ \\
\hline & Production level accomplished & PRODLEVEL V4 & $1-4$ & Kingsley and Melkers (1999) \\
\hline & Barriers encountered & MARKETBARRIERS V5 & $\begin{array}{l}\text { 1. Project specifications, 2. Customer lack of focus, } \\
\text { 3. Technology change, } 4 \text { Economic reasons, and } \\
\text { 5. Objectives discrepancies }\end{array}$ & $\begin{array}{l}\text { Decter et al. (2007), Christensen (1997), Venkatesh and } \\
\text { Davis (2000); Greiner and Franza (2003); Moore (1991), Malhotra (1999) }\end{array}$ \\
\hline & Project added value for the firm & PROJECTADDED V6 & $\begin{array}{l}\text { 1. Growth, 2. New markets, 3. Competitivity, and } \\
\text { 4. Image. }\end{array}$ & $\begin{array}{l}\text { Tatikonda and Rosenthal (2000a,b); Stock and Tatikonda (2000); } \\
\text { Tatikonda and Montoya-Weiss (2001), Stock and Tatikonda (2008) }\end{array}$ \\
\hline \multirow[t]{7}{*}{ The firm } & Size & SIZE V7 & 1 Micro firm, 2 SME, Large & Kumar and Saqib (1996), Cooper and Bruno (2000) \\
\hline & $\begin{array}{l}\text { Firm evolution, } 7 \text { years later } \\
\text { Technology Added value for } \\
\text { the firm }\end{array}$ & $\begin{array}{l}\text { GROWTH V8 } \\
\text { TECHADDED V9 }\end{array}$ & $\begin{array}{l}\text { 0. It disappeared, } 1 \text {. It shrunk, equal, } 3 \text {. It grew } \\
\text { 1. New working procedures, } 2 \text {. Image, and } \\
\text { 3. Competitivity. }\end{array}$ & Löfsten and Lindelöf (2002), Ghani et al. (2002) \\
\hline & $\begin{array}{l}\text { Was the firm successful in selling } \\
\text { the new technology? }\end{array}$ & TECHSALES V10 & $1-0$ & $\begin{array}{l}\text { Stock and Tatikonda (2004); Im, and Workman (2004), } \\
\text { Crick and Jones (2000), Sirgy and Su (2000) }\end{array}$ \\
\hline & Industry technology level & TECHLEVEL V11 & $1-3$ & $\begin{array}{l}\text { Kumar and Saqib (1996); Tatikonda and Rosenthal (2000a,b); } \\
\text { Stock and Tatikonda (2000); Tatikonda and Montoya-Weiss (2001), } \\
\text { Yang and Liu (2006), Stock and Tatikonda (2008) }\end{array}$ \\
\hline & Global valorisation of the program & PROGRVALOR V12 & $1-5$ & \\
\hline & Project direct job creation & EMPLOYCREAT V13 & $\begin{array}{l}\text { Job creation directly associated to the developed } \\
\text { technology }\end{array}$ & $\begin{array}{l}\text { Campbell et al. (2009), Link (1993); Feldman and Kelley (2003); Pavelin and } \\
\text { Porter (2008), Rogers (2004) and Quetglás and Grau (2002) }\end{array}$ \\
\hline & Project impact in industry & IMPACT INDUSTRY V14 & $1-0$. Has the project meant an impact in its sector? & Pavelin and Porter (2008), Dohse (2000), Eickelpasch and Fritsch (2005) \\
\hline \multirow{5}{*}{$\begin{array}{l}\text { Relationship with } \\
\text { the research }\end{array}$} & Previous working experience & PREVIOUS EXP V15 & $1-0$ & Tatikonda and Rosenthal (2000a,b); Stock and Tatikonda (2008); \\
\hline & $\begin{array}{l}\text { Did the centre understood the } \\
\text { firm requirements? }\end{array}$ & UNDERSTAND V16 & $1-0$ & $\begin{array}{l}\text { Rogers (2001); Sung and Gibson (2005), Arvanitis et al. (2005), } \\
\text { Link and Scott (2003), Santoro and Gopalakrishnan (2001) }\end{array}$ \\
\hline & $\begin{array}{l}\text { Knowledge of the firms needs } \\
\text { by research centre }\end{array}$ & KNOWLEDEGE V17 & $1-0$ & \\
\hline & $\begin{array}{l}\text { Global valorisation of the centre } \\
\text { performance }\end{array}$ & CENTERVALOR V18 & $1-3$ & \\
\hline & $\begin{array}{l}\text { Did the firm continued the working } \\
\text { relationship with the centre? }\end{array}$ & CONTINUITY V19 & $1-0$ & \\
\hline
\end{tabular}




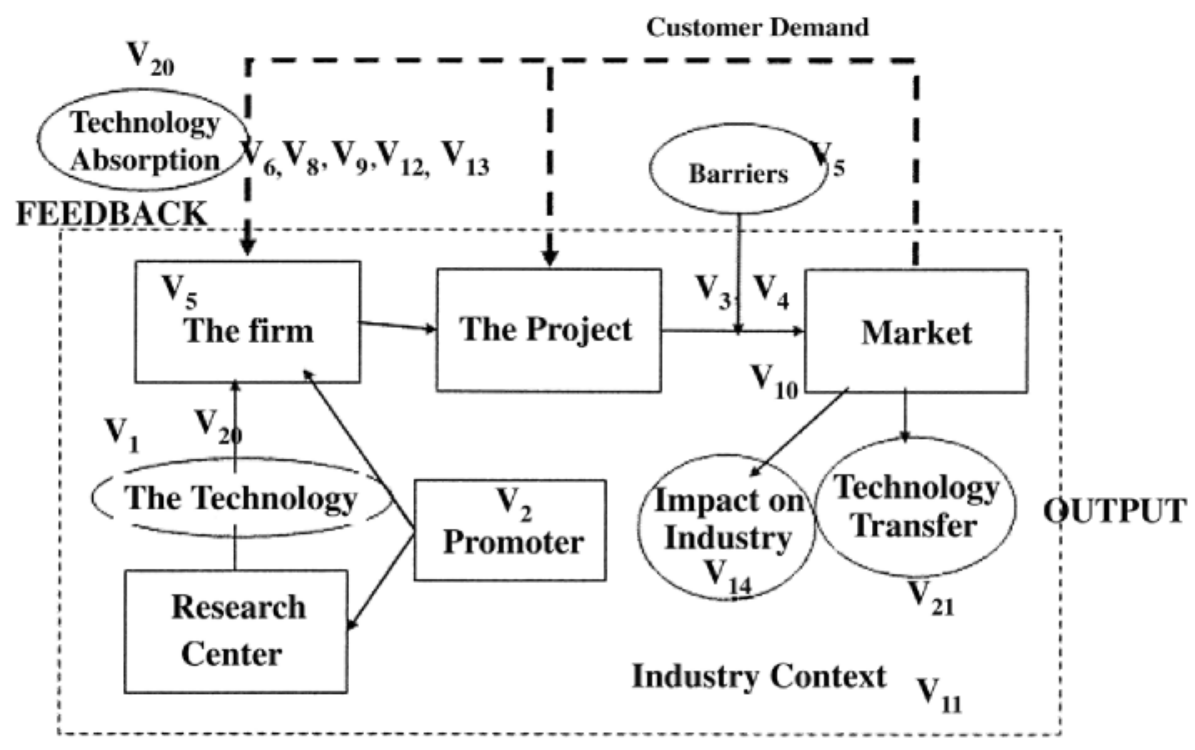

Fig. 5. Model scheme.

\subsection{Variables: developing new measures}

The interviews followed a pattern of detailed questions which are shown in Table 1 . The questions were related to the firm, the context of the project, the output of the project and its consequences. Table 1 summarises the questions and the variables that have been drawn from them, as well as their values.

The level of production pertained to a scale according to the number of units produced. The complexity was measured by the technical characteristics of the project.

The questionnaire considered a group of variables that correspond to the dimensions of the contingent effectiveness model proposed by Bozeman (2000).

In order to analyse the process we follow a simple model which, based on the theory and framework described above, includes two original ordinal additive variables to capture all the technology flows originating within a technology absorption and transfer process as accomplished by the program described. The process starts at the research centre which will develop the technology application with the participant firm. The participant firm, if its marketing process is successful, will transfer (market) the technology to the final industry customer. Therefore we have two measurable impacts: absorption (at the individual firm's level) and transference (at the general industry level). These will have as a consequence an impact on the firm and its environment (the industry). A number of input variables linked to each of the process participants (research centre, the firm, the coordination entity and the industry) will influence the process. The object to be transferred will be the technology itself and its complexity will be the influencing variable.

The attached Fig. 5 depicts the hypothesized model relating all construct variables. The firm (variables V7 to V13) is related through the developed technology with the research centre (variables V15 to V19). The proposer V2 acts as a promoter of the advanced technology development. The developed project (V3 to V6) will have a certain output, represented by the new high tech product sales (V10) and will, as well, generate a feedback in the firm by means of technology absorption (V20). The project will need to overcome various market barriers such as defective project specifications, a lack of focus towards customers, technology change (i.e., the disruptive change from ASICS to FPGAS), economic matters, and discrepancies between participants on objectives). As the survey demonstrated, the most relevant barrier was the lack of customer focus, especially when the technology involved was complex.

As the results of the statistical analysis ${ }^{2}$ show, a relevant ingredient of the process is based on the relationships between the firm and the research centre. Thus, the variable RELRESEARCH(V20) (Arvanitis et al., 2005; Hubbard, 1998; Sung and Gibson, $2005)$ is created to summarise the firm's relationship with the research centres. This secondary variable is the result of adding all the variables related: KNOWLEDGE(V17) + PREVIOUSEX(V15) + UNDERSTAND(V16) + CENTERVALOR(V18) + CONTINUITY (V19) $(\alpha$ Cronbach $=.699)$, which can be explained as the existence of previous working experience between the firm and the centre, the centre understands the firm's requirements, a knowledge of the firm's needs by the research centre, the global valorisation of the centre performance and the fact that the firm continues its working relationship with the centre after the project ends. 
Table 2

Bilateral correlations.

\begin{tabular}{|c|c|c|c|c|c|c|c|c|c|c|}
\hline & & TECHTRANS & EMPLYCREAT & TECHLEVEL INDUSTRY & TECHCOMPLEXITY (V1) & SIZE (V7) & MARKET BARRIERS & GROWTH & RELRESEARCHCENTER & IMPACT INDUSTRY \\
\hline \multirow[t]{2}{*}{ TECHTRANS } & Correl. Pearson & & $.714(* *)$ & & $-.671(* *)$ & & $.713(* *)$ & $.579(* *)$ & $.724(* *)$ & $.636(* *)$ \\
\hline & Sig. & & .000 & & .000 & & .000 & .005 & .000 & .000 \\
\hline \multirow[t]{2}{*}{ EMPLYCREAT } & Correl. Pearson & $.714(* *)$ & & $-.218\left(^{*}\right)$ & $-.526(* *)$ & $.543(* *)$ & $.419(* *)$ & $.879(* *)$ & $.634(* *)$ & $.583(* *)$ \\
\hline & Sig. & .000 & & .029 & .000 & .000 & .000 & .000 & .000 & .000 \\
\hline TECHLEVELINDUSTRY & $\begin{array}{l}\text { Correl. Pearson } \\
\text { Sig. }\end{array}$ & & $\begin{array}{l}-.218\left(^{*}\right) \\
.029\end{array}$ & & & & & $\begin{array}{c}-.233\left(^{*}\right) \\
.020\end{array}$ & & \\
\hline \multirow{2}{*}{ TECHCOMPLEXITY (V1) } & Correl. Pearson & $-.671\left(^{* *}\right)$ & $-.526(* *)$ & & & & $\left.-.6399^{(* *)}\right)$ & $-.342(* *)$ & $-.206\left(^{*}\right)$ & $-.297(* *)$ \\
\hline & Sig. & .000 & .000 & & & & .001 & .000 & .040 & .003 \\
\hline \multirow[t]{2}{*}{ SIZE(V7) } & Correl. Pearson & & $.543(* *)$ & & & & & $.290(* *)$ & $.396\left(^{* *}\right)$ & $\left..199^{*}\right)$ \\
\hline & Sig. & & .000 & & & & & .003 & .000 & .047 \\
\hline \multirow[t]{2}{*}{ MARKETBARRIERS (V5) } & Correl. Pearson & $.713(* *)$ & $.419(* *)$ & & $-.639(* *)$ & & & $.215(*)$ & $.247\left(^{*}\right.$ & $.255\left(^{*}\right)$ \\
\hline & Sig. & .000 & .000 & & .001 & & & .032 & .013 & .010 \\
\hline \multirow[t]{2}{*}{ GROWTH } & Correl. Pearson & $.579(* *)$ & $.879(* *)$ & $-.233(*)$ & $-.342(* *)$ & $.290(* *)$ & $.215\left(^{*}\right)$ & & $.436(* *)$ & $.407(* *)$ \\
\hline & Sig. & .005 & .000 & .020 & .000 & .003 & .032 & & .000 & .000 \\
\hline \multirow[t]{2}{*}{ RELRESEARCHCENTER } & Correl. Pearson & $.724(* *)$ & $.634(* *)$ & & $-.206\left(^{*}\right)$ & & $.247\left(^{*}\right)$ & $.436(* *)$ & & $.645(* *)$ \\
\hline & Sig. & .000 & .000 & & .040 & & .013 & .000 & & .000 \\
\hline \multirow[t]{2}{*}{ IMPACTINDUSTRY } & Correl. Pearson & $.636(* *)$ & $.583(* *)$ & & $-.297(* *)$ & $.199(*)$ & $.255\left(^{*}\right)$ & $.407(* *)$ & $.645(* *)$ & \\
\hline & Sig. & .000 & .000 & & .003 & .047 & .010 & .000 & .000 & \\
\hline
\end{tabular}

*** $p<0.001$ 
Technology adoption and absorption have been related to the relationships between the technology developing instigator and its customer, as well as the mutual developed trust in the case of technology intensive cases (Hubbard, 1998). Following this line of thought, we have proposed the variable TECHABS(V21) = RELRESEARCH(V20) + PROGRVALOR(V12) $(\alpha$ Cronbach = .689), with the purpose of explaining the technology absorption level developed in the project (Kingsley et al., 1996; Kingsley and Farmer, 1997).

Secondly, we developed TECHTRANS(V22) = PRODLEVEL (V4) + MARKETED (V3) + TECHSALES V10 $(\alpha$ Cronbach $=792)$, which explains the level of technology transfer accomplished in the project (Kingsley et al., 1996; Kremic, 2003).

Working with additive variables, we scale and give a score to the aspects of absorption and transfer from a dynamic point of view which reduces the complexity of the variables, keeps the information value and adds robustness to the model to be built as the sum of useful variables. This defined scale spans points 1 to 6 , in the TECHTRANS(V22) case, and points 2 to 10 for the TECHABS (V21) variable, both being ordinal variables.

We used multivariate analysis, factorial, cluster and discriminant techniques to fulfil our objective of identifying different groups of firms in the process in which technology transfer occurs.

\section{Results}

A first bilateral correlation analysis (see Table 2) of the variables involved showed that technology transference is correlated with a number of key input variables such as technology complexity, market barriers and relationships with the research centre. It is correlated, as well, with other output variables such as impact in the firm's industry, creation of employment and growth. It must be pointed out that variables such as the firm's size, industry context or project organization (Proposer V2) were not found to be relevant.

In order to test the proposed construct and the second hypothesis, a stepwise regression analysis was developed. It concluded with the following model

\begin{tabular}{lccc}
\hline Model & \multicolumn{1}{c}{ Standardized coefficients } & Sig. & Typ. error \\
Dependent variable: TECHTRANS(V22) & Beta & .707 \\
\hline Constant & .266 & .002 \\
MARKETBARRIERS (V5) & -.257 & .002 \\
TECHCOMPLEXITY (V1) & .269 & .002 \\
PROGRAMVALORIZATION(V12) & .183 & .016 \\
RELRESEARCH(V20) & .202 & .008 \\
TECHADDED(V9) & -.156 & .038 \\
PROJADDED(V6) & & \\
\hline
\end{tabular}

$R=.780$.

It can be observed that, according to this model, the dependent variable TECHTRANS(V22) is related positively with the firm's program valorisation (those firms with a higher valorisation of the program will have significant probability of attaining a higher technology transfer), with the relationships with the research centre (those firms with a better relationship with the research centre will have significant probability of attaining a higher technology transfer), with the technology value added (those firms stating that the project contributed to their competitivity had a higher probability of attaining a higher technology transfer). However, the relationship was negative in the case of the contribution of the project with the firm's image, the complexity of the technology and the market barriers (lack of customer focus).

It appears that variables such as size of the firm, industry context (technology level), or the role of the proposer agent (V2) do not have any influence on the model.

Table 3

Results in the multivariate analysis.

\begin{tabular}{|c|c|c|c|}
\hline \multirow[b]{2}{*}{ Variables } & \multicolumn{3}{|c|}{ Cluster analysis: identified groups } \\
\hline & 1 & 2 & 3 \\
\hline $\begin{array}{l}\text { TECHTRANSF } \\
F \text { test } 166,562^{* * *}\end{array}$ & 2.21 & 5.14 & 1.68 \\
\hline $\begin{array}{l}\text { TECHABS } \\
F \text { test } 116.628^{* * * *}\end{array}$ & 4.38 & 8.51 & 7.44 \\
\hline $\begin{array}{l}\alpha=0.7911 \\
79.592 \% \text { amount of total variance explained }\end{array}$ & $n=24$ & $n=51$ & $n=25$ \\
\hline $\begin{array}{l}\text { TECHTRANSF } \\
\text { TECHABS }\end{array}$ & $\begin{array}{l}\text { Discriminant analysis } \\
\text { Wilks' lambda } \\
.226^{\text {t***}} \\
.294^{\text {****}}\end{array}$ & \multicolumn{2}{|c|}{$\begin{array}{l}\text { Score classification } 99.0 \% \text { into original } \\
\text { groups. }\end{array}$} \\
\hline
\end{tabular}

TECHABS $=$ RELRESEARCH + PROGRVALOR.

TECHTRANS $(V 10)=$ PRODLEVEL + MARKETED + TECHSALES (V10).

*** Significant at $p<0.01$. 
Table 4

Final clustering descriptive statistics.

\begin{tabular}{|c|c|c|c|c|}
\hline Cluster & & TECHTRANS & TECHABS & EMPLYCREAT \\
\hline \multirow[t]{5}{*}{1} & $N$ & 24 & 24 & 24 \\
\hline & Mean & 2.2083 & 4.3750 & 1.20 \\
\hline & S. deviation & 1.1025 & .8754 & 2.12 \\
\hline & Minimum & 1.00 & 2.00 & .00 \\
\hline & Maximum & 5.00 & 6.00 & 4.36 \\
\hline \multirow[t]{5}{*}{2} & $N$ & 51 & 51 & 51 \\
\hline & Mean & 5.1373 & 8.5098 & 12.01 \\
\hline & S. deviation & .8251 & 1.1202 & 4.45 \\
\hline & Minimum & 3.00 & 6.00 & .00 \\
\hline & Maximum & 6.00 & 10.00 & 15.88 \\
\hline \multirow[t]{5}{*}{3} & $N$ & 25 & 25 & 25 \\
\hline & Mean & 1.6800 & 7.4400 & 7.99 \\
\hline & S. deviation & .7483 & 1.2275 & 3.52 \\
\hline & Minimum & 1.00 & 6.00 & .00 \\
\hline & Maximum & 3.00 & 10.00 & 11.74 \\
\hline \multirow[t]{5}{*}{ Total } & $N$ & 100 & 100 & 100 \\
\hline & Mean & 3.5700 & 7.2500 & 8.89 \\
\hline & S. deviation & 1.8382 & 2.0019 & 5.32 \\
\hline & Minimum & 1.00 & 2.00 & .00 \\
\hline & Maximum & 6.00 & 10.00 & 15.88 \\
\hline
\end{tabular}

$p<.000$ in all cases.

In order to test the first and third hypotheses two variables were used in the model: TECHTRANS(V22) (technology transfer) and TECHABS(V21) (technology absorption) previously defined in 4.1. These explain 79.592\% of the total variance, according to the applied factor analysis. According to the Bartlett $X^{2}$ test ( $F$ value) the total amount of variance explained is significant at $p<.01$ (see Table 3).

The data analysis involved two stages. The first stage was divided into two steps. Step one included the most adequate identification of the groups, using an agglomerative hierarchical method. The results obtained, through the dendrogram (using average linkage) and the agglomeration coefficient, $t$ clearly indicated three groups as a focus structure. The second step involved a non-hierarchical clustering, $k$-means, with three groups included in order to validate the first step. We observed a $95 \%$ concordance between two methods used. The results identified three final clusters with significant differences in the two variables in each group, according to ANOVA (F) test significance at $p<.01$. We also show the number of cases in each cluster (see Table 4 ).

The second stage consisted of a discriminant analysis in order to corroborate the clustering results, as a complementary method of adding robustness to the identification group's process, as suggested by Hair, Anderson, Tatham and Black (1999). As can be seen in Table 4 , the two variables used to predict group classification work at $p<.01$ significance in the $F$ test. As a result, the concordance classification of the predicted groups using canonical functions with the original groups, achieved a $99.0 \%$ correctly classified score.

A new variable, BELONGING(V23), has been set up to indicate the affiliation to a cluster group for future use.

As a result, we have drawn the map of the population structure in Fig. 5. In this figure, we classify the three groups according to the values taken by the variables TECHTRANS(V22) and TECHABS(V21). This map is the result of the clustering sample using the value mapping methodology and the multivariate model applied.

The values taken by the descriptive statistics in each group formed are represented in Table 4.

The output of value mapping methodology in our case shows three clusters of firms, which occupy three quadrants of the TECHTRANS(V22)/TECHABS(V21) matrix (Fig. 6) proposed by the value mapping methodology. The main characteristics of each area are the following:

\subsection{Cluster Group 1}

It consists of $50 \%$ of the projects from both phases. The cluster can be characterized by medium-low technology transfer and absorption levels, medium to high technology complexity projects, a medium to low relationship with the research centre, and an intermediate appreciation of the program value. Composed of medium-size firms, and with a low growth of employment in the previous seven years, these firms recognized improvement in their level of competitiveness as the main contribution of the project, an improvement in the firm's image as the main contribution of the technology. These firms claimed that one of the main barriers to the project's success was the lack of customer focus. These firms recognized that the project had had a very low impact in their sector (social impact). The technology level of these firms was medium to high. The project job creation mean value was rather low (1.20).

This group, composed of 24 cases, could be classified as "on the shelf projects", according to the value mapping approach (Kingsley et al., 1996). These projects did not reach the utilisation stage and could be considered as a commercial failure. The main barriers mentioned in the survey replies were a lack of customer focus and a lack of understanding by the research centre of the firm's needs. These factors combined with a high technology complexity level contributed to a higher risk. Perhaps their excessive ambition, combined with a weaker relationship with the research centre, contributed to their failure. These could be considered 
a

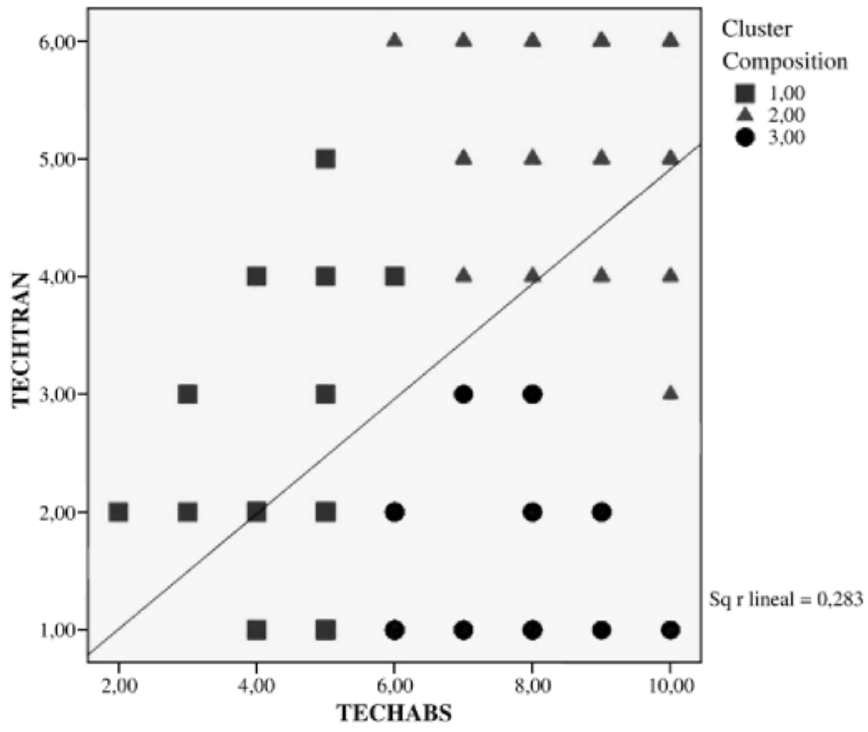

b

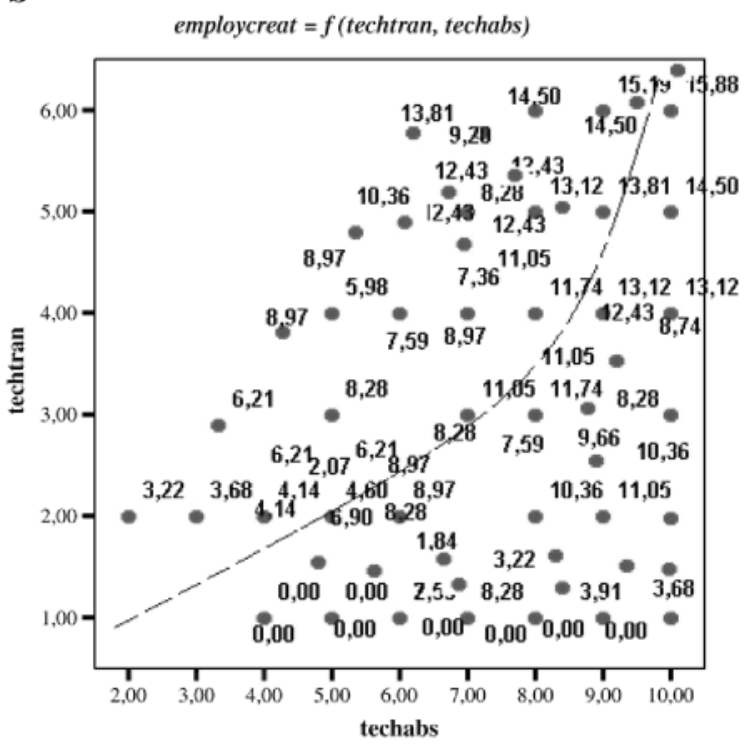

Fig. 6. (a) Map of the clustered studied population, (b) regression function of EMPLOYCREAT. Clustering structure.

extreme examples of technology push cases given the fact that the majority of the projects were proposed by the research centre or the program organization. It should be pointed out that these projects were carried out by firms which later either disappeared or showed negative growth.

\subsection{Cluster Group 2}

$65 \%$ of the projects in this group belonged to the second program phase. This group, characterized by high technology transfer and absorption level, showed a strong relationship with the research centre and a high appreciation of the program's value. Composed of medium to large-size firms, it showed considerable employment growth during the succeeding seven years. These firms recognized improvement in competitiveness as the main contribution of the project, and the development of the firm's image as the main contribution of the technology. These firms also claimed that the main barriers to the project's success were the necessary technological changes and the subsequent financial limitations. $80 \%$ of these firms recognized the very high impact of the project in their sector. The job creation mean value was high (12.01). This group showed a high social coherence in its project approach.

This cluster, composed of 51 cases, corresponds to the group of projects identified by Value Mapping as "sponsored induced transfer" (Kingsley et al., 1996). The success of these projects is due to the combination of technology push policies and demand pull efforts. These projects had a strong end-user approach, the project idea having been suggested by the final user. This group was also favoured by a strong and lasting relationship with the research centre. The participating firms experienced strong growth and the declared impact of the project in the industry was also high.

\subsection{Cluster Group 3}

This group was comprised of $50 \%$ of projects from both phases. It was characterized by a medium technology transfer and a high technology absorption level, a relatively strong relationship with the research centre and a medium to high appreciation of the program's value. This group is composed of medium-size firms which had had a growth in employment in the succeeding seven years. These firms recognized an improvement in the firm's image as the main contribution of the project and the development of their competitiveness as the main contribution of the technology. These firms also claimed that the main barrier to the project's success was a lack of knowledge of the requirements of the final client. 50\% of these firms recognized a very high impact of the project in their sector.

This group is composed of 25 projects and is defined as "absorption cases" by Value Mapping (Kingsley et al., 1996). The projects were successful in the absorption phase by the project participant firm but were not able to proceed with the technology transfer process to third parties. Still, although the projects benefited from their demand pull characteristics and a strong relationship with the research centre, there was a failure in detecting the real demand of the final user or the context constraints. Nevertheless, the technology absorption contributed to improving the firms' competitiveness and growth. In this case the taxonomy of the group also coincides with that pointed out by Value Mapping literature. 
In our study we were unable to find projects which would fit in the "market induced" projects group proposed by Kingsley et al. (1996). These projects are characterized by high technology transfer and a low absorption level; they require a lower level of research with a higher level of development input while having a high technical and market risk. The reasons for this deviation from our initial hypothesis may be due to two factors. The technology considered was complex, meaning a breakthrough innovation effort in their industry and was at the time not mature enough. This situation required a strong effort in cooperation and coordination from the research centres and user firms. Thus, a high absorption level seems to be a prerequisite for achieving a further technology transfer phase. Moreover, the RVM model doesn't seem to exactly fit advanced technology programs.

Finally, in relation to the social impact represented by the employment created directly by the project, a regression model was developed, a function of both technology transfer and technology absorption (see Fig. 6b representing the dispersion graph).

Thus, the resulting regression model is as follows:

\begin{tabular}{|c|c|c|c|}
\hline \multirow[t]{2}{*}{ Model } & Standardized coefficients & $t$ & Sig. \\
\hline & Beta & B & Standard error \\
\hline Constant & & -3.348 & .001 \\
\hline TECHABS(V21) & .511 & 6.450 & .000 \\
\hline TECHTRANS(V22) & .343 & 4.330 & .000 \\
\hline
\end{tabular}

Dependent variable: EMPLOYCREAT(V13).

$R=.859$.

In the same direction, a second model was developed representing the impact in the firm's sector. However, since IMPACTINDUSTRY(V14) is a dichotomic variable, we have followed a Stepwise Log it Model and the results are as follows for the optimum model:

\begin{tabular}{llllrr}
\hline & & Wald & g1 & Sig. & Exp(B) \\
\hline Step 2(b) & TECHTRANS(V22) & 9481 & 1 & .002 & 1.625 \\
& TECHABS(V21) & 10,247 & 1 & .001 & .000 \\
Constant & 19,506 & 1 & .655 \\
& & & 007 \\
\hline
\end{tabular}

This model is capable of classifying correctly $79.5 \%$ of the cases for IMPACTINDUSTY. It has to be pointed out here that other variables such as the industry technology level TECHLEVEL(V11) or technology complexity TECHCOMPL(V1) have been excluded from the Log it model.

Both results justify the social impact of the project by the combination of technology transfer and technology absorption. However, the first variable is the sole objective and measurable variable of both since the second only reflects the opinion of the manager on the project outcome.

\section{Discussion and conclusions}

The results of the statistical analysis show that we were able to validate the construct partially, and consequently, the proposed hypotheses. Accordingly, the process of technology diffusion follows a heterogeneous path among the firms participating in the program confirming Hypothesis 1 . The level of technology transfer is contingent on a number of factors as proposed by the literature but not on all. The key factors that proved to be related to technology transfer were: technology complexity, market barriers and especially a lack of customer focus, the relationships with the research centre as well as the firm's feedback related to the added value of the project and technology.

Taking into account both composite variables, technology transfer and technology absorption as classifying variables, three clusters of firms with different behaviours and impacts were found.

In relation to the second hypothesis, we found that the efficiency of technology adoption, as measured by its impact, can be measured by the degree to which it has been transferred by the firm to third parties since the absorption process seems to be a prerequisite in the case of advanced technology.

Finally, the third hypothesis was validated as well. Social impact measured in terms of project job creation or impact in the firm's industry seems to be dependent on both technology absorption and transference in the case of advanced technology. This could be explained by the complex knowledge absorption process associated to microelectronics.

According to these findings, we can also conclude that value mapping can be utilised and is a valid method for classifying project output and social impacts with certain limitations when considering the diffusion of advanced complex technology, as in our case. There is a deviation in the project taxonomy, since only three groups are clearly differentiated in the technology transfer versus technology absorption matrix, as opposed to the four groups depicted in the value mapping model. In our case, the utilisation of composite variables (TECHTRANS/TECHABS) has contributed to providing two sets of continuous variables which provide a stronger statistical analysis than in the original RVM model proposal (Kingsley et al., 1996).

This can be attributed to the fact that microelectronics needs complex technology, and requires a sophisticated process for its transfer with a learning (absorption) phase as a prerequisite. Again, this raises the question of whether advanced technology 
requires a different consideration than the original RVM approach. Observing our modified model proposal in Fig. 6, which the empirical results seem to confirm, a linear progression model is suggested where technology absorption and transfer are aligned. These conclusions point to modified model assumptions since the original RVM model considers that technology absorption and transfer follow independent paths. However, the fact that these authors (Kingsley \& Farmer, 1997) subsequently discussed the issue of technology absorption versus technology transfer in the case of conventional technology has to be considered.

Furthermore, the projects were developed in a highly uncertain technological environment due to the disrupting technology curves of microelectronics and a changing economy of scale. This context alters the project environment from the strategic point of view of the firm and the industry and again modifies the original RVM approach based on conventional technologies.

The results also highlight the importance of the relationship between the research centre and the firm in the absorption and transference process and the relatively weak influence of the complexity of the technology of each project, and the recipient industry's technology level, in the success of the project transference. The importance of customer focus in the case of the technology transfer shows the influence of the adopting context in technology transfer as the technology diffusion literature points out. A correlation between social impact and the technology absorption and transference levels was also found.

The paper has certain limitations. First, economic data could have supported the social impact with sales figures attributed to the new technology, or the impact in third parties but these were available only for a limited number of firms. However, job creation was directly attributed to the developed technology. Secondly, the level of technology absorption could have been estimated by analysing the firms' parallel development and the training outputs of the program, but again the relevant data were scarce. Thirdly, and most important from our point of view, the evaluation could also have considered the development of research centres, since some program impacts were detected here, but in this case the evaluation resources did not cover this aspect of the program. The difficulties such as indirect jobs, knowledge transfer to the environment, etc. associated with measuring the indirect impact of the project have been evident as well.

Further research should be carried out to consider the roles of research centres and outside consultants. $75 \%$ of the projects were carried out by only five centres, some of which exhibited certain attributes of leadership (according to the opinions expressed by the firms). This clearly facilitated the project's success and performance.

\section{Notes}

1. In general we will concentrate on the ASICS development and design line of the GAME program since it encompasses the majority of the resources.

2. As the literature points out, the efficiency of a diffusion program is difficult to measure given the indirect effects of these actions (Albors, Sweeney, \& Hidalgo, 2005).

3. See Hair et al. (1999) to review these statistical techniques.

\section{Acknowledgments}

The authors would like to thank Fundacion Cotec for their support of this research. We would also like to thank the anonymous reviewers for their valuable comments and suggestions.

\section{References}

Albors, J., Sweeney, E., \& Hidalgo, A. (2005, June). Transnational technology transfer networks. A review of the state-of-the art and an analysis of the European IRC network. Production Planning \& Control, 16(4), 413-423.

Arvanitis, S., Kubli, U., \& Worter, M. (2005, December). Determinants of knowledge and technology transfer activities between firms and science institutions in Switzerland: An analysis based on firm data Zurich: Swiss Federal Institute of Technology.

Audretsch, D. B., Link, A. N., \& Scott, J. T. (2002, January). Public/private technology partnerships: Evaluating SBIR-supported research. Research Policy, 31 (1), $145-158$.

Autio, E., \& Laananen, T. (1995). Measurement and evaluation of technology transfer: Review of technology transfer mechanisms and indicators. International Journal of technology Management, 10(7-8), 643.

Bass, F. M. (1969). A new product growth model for consumer durables. Management Science, 15, 215-227.

Bozeman, B. (2000). Technology Transfer and public policy: A review of research and theory. Research Policy, 29, 627-655.

Bozeman, B., \& Kingsley, G. (1997). R\&D Value mapping: A new approach to case study valuation. Journal of Technology Transfer, 22(2), 33-42.

Campbell, S., Shipp, S., Mulcahy, T., \& Allen, T. W. (2009). Informing public policy on science and innovation: The Advanced Technology Program's experience. Journal of Technology Transfer, 34, 304-319.

Chandy, R. K., \& Tellis, G. J. (2000). The incumbent's curse? Incumbency, size and radical product innovation. Journal of Marketing, 64(3), 1-17.

Christensen, C. (1997). The innovator's dilemma Boston: Harvard Business School Press.

Cooke, P., Davies, C., \& Wilson, R. (2002). Innovation Advantages of Cities: From Knowledge to Equity in Five Basic Steps. European planning studies, 10 (2), $233-250$.

Cooper, A. C., \& Bruno, A. V. (2000). Success among high technology firms. In D. J. Storey (Ed.), Small Business: Critical perspectives on Business and Management. New York: Routledge.

Crick, D., \& Jones, M. (2000). Small high-technology firms and international high-technology markets. Journal of International Marketing, 8(2), 63-85.

David, P. A. (1986). "Technology Diffusion, Public policy and industrial competitiveness", in Davies, S. (1979): The Diffusion of Process Innovations. Cambridge University Press, Cambridge.

Davies, S. (1979). The Diffusion of Process Innovations, Cambridge University Press.

Decter, M., Bennett, D., \& Leseure, M. (2007). University to business technology transfer, UK and USA comparisons. Technovation, 27(3), 145-155.

Dohse, D. (2000). Technology policy and the regions: The case of the BioRegio contest. Research Policy, 29(9), 1111-1133.

Eickelpasch, A., \& Fritsch, M. (2005). Contests for cooperation: New approach in German innovation policy. Research Policy, 34(8), $1269-1282$.

Ergas, J. (1987). Does technology policy matter? In Guile, \& Brooks (Eds.), Technology and global industry. Washington: National Academy Press.

Estrin, L. AND Foreman, J. T. (2003). Overcoming Barriers to Technology Adoption in Small Manufacturing Enterprises (SMEs), Carnegie Mellon University and Software Engineering Institute Material, N.Y. 
Feldman, M. P., \& Kelley, M. R. (2003). Leveraging research and development: Assessing the impact of the U.S. Advanced Technology Program. Small Business Economics, 20(2), 153-165.

Fundación Cotec, (1997). "Report on the GAME initiative", September, Madrid.

Gatignon, H., \& Robertson, T. S. (1989). Technology diffusion: An empirical test of competitive effects. Journal of Marketing, 35, $35-49$.

Georghiou, L., \& Roessner, D. (2000). Evaluating technology programs: Tools and methods. Research Policy, 29(4-5), 657-678.

Geroski, P. A. (2000). Models of technology diffusion. Research Policy, 29(4/5), 603-625.

Ghani, K. A., Jayabalan, V., \& Sugumar, M. (2002). Impact of advanced manufacturing technology on organizational structure. Journal of High Technology Management Research, 13(2), 157-175.

Gourlay, A., \& Pentecost, E. (2002). The determinants of technology diffusion. Evidence from the UK financial sector. Manchester School, 70(2), $185-203$.

Green, G. C., Collins, R. W., \& Hevner, A. R. (2004). Perceived control and the diffusion of software process innovations. Journal of High Technology Management Research, 15, 123-144.

Greiner, M. A., \& Franza, R. M. (2003). Barriers and bridges for successful environmental technology transfer. Journal of Technology Transfer, $26,167-177$.

Hahn, Y. H., \& Yu, P. (1999). Towards a technology policy: The integration of generation and diffusion. Technovation, 19(3), 177-186.

Hair, J. F., Anderson, R. E., Tatham, R. L., \& Black, W. C. (1999). Multivariate Data Analysis, 5th edition: Prentice Hall.

Hall, B. H., \& Khan, B. (2003). Adoption of new technology. NBER Working Papers, Vol. 9730 : National Bureau of Economic Research, Inc.

Hubbard, T. (1998). Why are process monitoring technologies valuable? The use of on-board information technology in the trucking industry. National Bureau of Economic Research Working Paper, Vol. 6482.

Im, S., \& Workman, J. P. (2004). Market orientation, creativity, and new product performance in high-technology firms. Journal of Marketing, 68(2), 114-132.

Kerr, S., \& Newell, R. G. (2003). Policy-induced technology adoption: Evidence from the U.S. lead phasedown. Journal of Industrial Economics, 51(3), 317-343.

Kingsley, G. (1993). The use of case studies in R\&D impact evaluation. In B. Bozeman, \& J. Melkers (Eds.), Evaluating RED impacts Methods and Practice (pp. 17-42). Kluwer.

Kingsley, G., Bozeman, \& Coker, K. (1996). Technology transfer and absorption: An R\&D value mapping approach to evaluation. Research Policy, 25, 967-995.

Kingsley, G., \& Farmer, M. C. (1997). Using technology absorption, an evaluation criterion. The case of a state R\&D program. Policy Studies Journal, 25(3), 436-450.

Kingsley, G., \& Melkers, J. (1999). Value mapping social capital outcomes in state research and development programs. Research Evaluation, 8(3), 165-175.

Kremic, T. (2003). Technology transfer: A contextual approach. Journal of Technology Transfer, 28, 149-158.

Kumar, N., \& Saqib, M. (1996). Firm size, opportunities for adaptation and in-house R \& D activity in developing countries: the case of Indian manufacturing. Research Policy, 25, 713-722.

Link, A. N. (1993). Evaluating the advanced technology program: A preliminary assessment of economic impacts. International Journal of Technology Management, $8($ No.6/7/8), 726-739.

Link, A. N., \& Scott, J. T. (2003). U.S. Science Parks: The diffusion of an innovation and its effects on the academic missions of universities. International Journal of Industrial Organization, 2, 1323-1356.

Löfsten, H., \& Lindelöf, P. (2002). Science Parks and the growth of new technology-based firms, academic-industry links, innovation and markets. Research Policy, $31(6), 859-876$.

Mahajan, V., Muller, E., \& Bass, F. M. (1991). New product diffusion models in marketing: A review and directions for research. In N. Nakicenovic, \& A. Grubler (Eds.), Diffusion of technologies and social behavior (pp. 125-177). New York: Springer.

Malhotra, Y. (1999). Bringing the adopter back into the adoption process: A personal construction framework of information technology adoption. Journal of High Technology Management Research, 10(1), 79-104.

Moore, G. A. (1991). Crossing the chasm: Marketing and selling high tech goods for mainstream customers. N.Y: Harper Business.

Mowery, D. (1995). The practice of technology policy. In P. Stoneman (Ed.), Handbook of the economics of innovation and technological change Oxford: Blackwell.

Norman, D. A. (1998). The invisible computer Cambridge, M.A: MIT Press.

Pavelin, S., \& Porter, L. A. (2008). The corporate social performance content of innovation in the U.K. Journal of Business Ethics, $80(4), 711-725$.

Quetglás, G. M., \& Grau, B. C. (2002). Aspects of university research and technology transfer to private industry. Journal of Business Ethics, 39(1-2), 51-58.

Reid, S. E., \& de Brentani, U. (2004). The fuzzy front end of new product development for discontinuous innovations: A theoretical model. Journal of Product Innovation Management, 21(3), 170-184.

Roberts, J. H., \& Lattin, J. M. (2000). Disaggregate-level diffusion models. In V. Mahajan, E. Muller, \& Y. Wind (Eds.), New-product diffusion models (pp. 207-236). Boston: Kluwer Academic Publishers.

Rogers, E. M. (1995). Diffusion of innovations. N.Y.: The Free Press.

Rogers, E. W. (2001). A theoretical look at firm performance in high-tech organizations: What does existing theory tell us? Journal of High Technology Management Research, (12), 39-61.

Rogers, E. W. (2004). The effect of perceptions of the employment game on cooperative knowledge behaviour in high-tech firms. Journal of High Technology Management Research, 15, 17-36.

Santoro, M. D., \& Gopalakrishnan, S. (2001). Relationship dynamics between university research centers and industrial firms: Their impact on technology transfer activities. Journal of Technology Transfer, 26(163), 171.

Sirgy, M. J., \& Su, C. (2000). The ethics of consumer sovereignty in an age of high tech. Journal of Business Ethics, 28(1), 1-14.

Stock, G. N., \& Tatikonda, M. V. (2004). External technology integration product and process development. International Journal of Operations \& Production Management, 24(7), 642-665.

Stock, G. N., \& Tatikonda, M. V. (2008). The joint influence of technology uncertainty and interorganizational interaction on external technology integration success. Journal of Operations Management, 26(1), 65-80.

Stoneman, P., \& Vickers, J. (1988). The assessment: The economics of technology policy. Oxford Review of Economic Policy, 4, I-XVI.

Subramanian, M., \& Youndt, M. A. (2005). The influence of intellectual capital on the types of innovative capabilities. Academy of Management Joumal, 48(3), 450-463.

Sung, T. K., \& Gibson, D. V. (2005). Knowledge and technology transfer grid: Empirical assessment. International Journal of Technology Management, 29(3-4), 216-230.

Tatikonda, M. V. (1999). An empirical study of platform and derivative product development projects. Journal of Product Innovation Management, 16(1), 326.

Tatikonda, M. V., \& Montoya-Weiss, M. M. (2001). Integrating operations and marketing perspectives of product innovation. Management Science, 47(1), 151-172.

Tatikonda, M. V., \& Rosenthal, S. R. (2000). Technology novelty, project complexity, and product development project execution success: A deeper look at task uncertainty in product innovation. IEEE Transactions on Engineering Management, 47, 74-87.

Tatikonda, M. V., \& Rosenthal, S. R. (2000). Successful execution of product development projects: Balancing firmness and flexibility in product innovation. Journal of Operations Management, 18(4), 401-425.

Teece, D. J. (1981). The market for know how and the efficient international transfer of technology. Annals of the American Academy of Political and Social Sciences, $458,81-96$.

Venkatesh, V., \& Davis, F. D. (2000). A theoretical extension of the technology acceptance model: Four longitudinal field studies. Management Science, 46(2), 186-204.

Yang, J., \& Liu, C. Y. (2006). New product development: An innovation diffusion Perspective. Journal of High Technology Management Research, 17(1), 17-26. 